\title{
Mental health problems and social disadvantages as predictors of teenage parenthood: A register-based population study of Swedish boys and girls
}

\author{
Sara Kalucza Umeå University, Sweden \\ sara.kalucza@umu.se
}

(Received January 2017

Revised October 2017)

http://dx.doi.org/10.14301/llcs.v9i2.444

\begin{abstract}
It has been argued that the relationship between mental health and teenage parenthood might be explained by the connection of social disadvantage and mental health. This paper embraces a life course approach and investigates the link between social and health disadvantages and teenage parenthood in Sweden, in attempt to disentangle experiences of early mental health problems from other social disadvantage factors. The research questions were explored through random intercept logistic models for panel data. The data for this study consists of all individuals born in Sweden between 1989 and 1994, drawn from Swedish population registers. The final models comprised 680,848 individuals who were followed throughout their teenage years. The results show that mental health problems in youth function as an independent predictor of teenage parenthood, even after adjusting for other social disadvantage factors. This observation applies for both boys and girls. Activities aimed at increasing the perceived life opportunities of youth and giving significance to life may be considered as means of preventing teenage parenthood through policy. This study suggests that such activities could be extended to include teenagers with mental health problems.
\end{abstract}

\section{Keywords}

Adolescence; adolescent parents; family; fertility; longitudinal; mental health; teenage parenthood

\section{Introduction}

Teenage pregnancy and teenage parenthood are often described as public health concerns with adverse outcomes for both mother and child (Cunnington, 2001; Lawlor \& Shaw, 2002). However, claims of casual links between further adverse life course outcomes and teenage parenthood have been disputed, with research finding that these continued adverse outcomes can partly or completely be attributed to aspects such as socioeconomic factors prior to birth (Cunnington, 2001; Furstenberg, 1991; Geronimus \& Korenman, 1992). Teenage parents tend to come from moredisadvantaged backgrounds, with lower parental income and education compared to their peers (Al-
Sahab, Heifetz, Tamim, Bohr, \& Connolly, 2012; Geronimus \& Korenman, 1992; Väisaenen \& Murphy, 2014). These pre-existing characteristics create social selection, where individuals from underprivileged backgrounds are more likely to become teenage parents and at the same time tend to fare worse later in life. Distinguishing between the risk factors for teenage parenthood and the consequences of becoming a parent early in life is crucial because the public framing of teenage parenthood as a societal problem puts teenage parents in a vulnerable position, with risk of social exclusion, stigmatisation, and deepening their disadvantage. 
This study adopts a life course approach to examination of the link between social and health disadvantages and teenage parenthood. It disentangles experiences of early mental health problems from other social disadvantage factors such as low parental education and income. The goal of the study is to determine whether selection of individuals with mental health issues into teenage motherhood or fatherhood is independent of other factors. I used data on individuals born 1989-1994 from the Swedish population register and modelled longitudinally.

The few available findings on the association between mental health and teenage parenthood support the notion that health-related disadvantages are precursors of teenage parenthood. However, the relatively low prevalence of teenage parenthood often inhibits study population sizes (e.g. Kovacs, Krol, \& Voti, 1994; Nilsen et al., 2012; Wahn \& Nissen, 2008; Woodward, Fergusson, \& Horwood, 2006). Low prevalence of teenage parenthood is especially evident with teenage fatherhood, which makes young fathers challenging to reach. Hence most previous studies focus solely on teenage mothers and do not provide evidence on their male counterparts (e.g. Barett, Katsiyannis, Zhang, \& Kingree, 2015; Hall, Kusunoki, Gatny, \& Barber, 2014; Nilsen et al., 2012; Väisanen \& Murphy, 2014; Wahn \& Nissen, 2008). This study overcame these limitations by using high-quality data covering the whole population, and includes both men and women.

\section{Background}

A socially disadvantaged background is associated with increased risk of further social exclusion over the course of life. Previous research demonstrated that teenage parenthood is one such event that links social disadvantages to later social exclusion, although the causal links are unclear (Gibb, Fergusson, Horwood, \& Boden, 2015; Olausson, Haglund, Weitoft, \& Cnattingius, 2001). The terms 'advantage' or 'disadvantage' can be understood as affiliation with a social group that possesses more or fewer opportunities, which place individuals at varying levels in the social hierarchy based on wealth, power, and prestige (Braveman \& Gruskin, 2003). Mental health problems are one example of a health-related disadvantage that is associated with stigma and social exclusion, often even after mental health treatment (Link, Phelan,
Bresnahan, Stueve, \& Pescosolido, 1999). It is plausible that such health-related disadvantage would be connected to events and states, like teenage parenthood, that eventually lead to social exclusion.

\section{Theoretical perspectives}

Several explanations of the association between social and health disadvantages and teenage parenthood have been presented. One suggested explanation is an increase in sexual risk-taking among teenagers with disadvantaged backgrounds (Kessler et al., 1997; Moilanen, 2015). However, others argue that teenage parenthood as a behavioural outcome is independent from sexual activity and pregnancy (Barrett et al., 2015).

The notion of opportunity costs might offer an explanatory mechanism for the two types of selection into young parenthood investigated in this study: socioeconomic background and mental health problems. Opportunity costs, a concept introduced by Becker (1960), centre on the fact that today's decisions are based on past experiences as well as on thoughts about the future. The opportunity cost of a choice is the value foregone by rejecting the most highly valued alternative, i.e. the cost that is sacrificed by choosing one alternative before another (Buchanan, 2008).

From this perspective, children incur two types of costs: direct and indirect, related to the time that could be spent on alternative activities such as participating in education or working for wages. Thus, the 'price' of children is lower for individuals who perceive their chances of acquiring education or income from work experience as low. Thus, we can expect a selection of low-income individuals into young parenthood. An important distinction here is that the perceived cost of a decision might not be the factual cost, but the type of cost depends on the available sets of information. Education and career success opportunities, or the risks and rewards of becoming a parent, may be over- or undervalued by the individual. Perceived opportunity costs therefore connect micro-level individual motivation and perception of an individual's alternatives to the macro-level structural opportunities available for work and education. In other words, the opportunity cost might be perceived as lower not only for individuals from low-income backgrounds, but for individuals with other types of disadvantaged backgrounds. Mental health problems in youth could appear to 
close the doors of lucrative career paths and high educational achievement, making the cost of early parenthood seem lower.

Parenthood choices can also be examined from the perspective of the theory of the value of children developed by Hoffman and Hoffman (1973). Hoffman, Thornton and Manis (1978) observed that both men and women seem to universally infuse children with the same types of values: love, companionship, and joy. However, individuals with lower education levels placed greater significance on these values (Hoffman et al., 1978) and it is hypothesised that this could be due to lesser-educated individuals having fewer alternative means to fulfil certain needs. This, in turn, could lead to lesser-educated individuals perceiving fewer beneficial opportunities in their future life and, hence, putting greater emphasis on what children might bring to their life. Hoffman's arguments may be extended to include social disadvantages such as mental health problems. I argue that mental health problems could also be perceived as a roadblock in self-esteem-yielding activities such as work and education. This perception leads to more dependence on family to fulfil their need for positive self-esteem.

Friedman, Hechter and Kanazawa (1994) provided further arguments pertaining to parenthood focused on the mechanisms of uncertainty reduction across the life course. Obtaining a stable job or long-term education are ways of reducing uncertainty in life; getting married and having children are other ways. According to Friedman et al. (1994), when one or more of these certain paths is perceived as blocked, the probability of another potential path increases. This is true even if the chosen path is associated with negative outcomes, since we focus on minimising uncertainty rather than maximising utility. Hence, young men and women suffering from mental health problems, and therefore facing more obstacles in education attainment and paid work, may choose early family formation as a route towards uncertainty reduction and reaching stability in their lives.

\section{Empirical research on mental health and early parenthood}

Connections between teenage parenthood and health-related disadvantages occurring due to mental health problems are less studied, compared to other types of disadvantages, and the existing results lead to varying conclusions. Kalucza, Hammarström and Nilsson (2015) did identify a selection, with men who had self-reported mental health problems in adolescence being less likely to become fathers, with no such relationship identified for women. Meanwhile, Jonsson et al. (2011) did not identify any selection into later adult parenthood by mental health for either men or women.

Carlson (2011) found a curvilinear relationship between mental health and age at first child, where both early and late timing of parenthood is related to a higher degree of depressive symptoms. Correspondingly, Selling, Carstensen, Finnstrom, Josefsson and Sydsjö (2009) found that women were more likely to give birth at ages 20-24 years if they had previously been hospitalised for mental health illnesses. After age 24, previously hospitalised women who had not yet had their first child, were less likely to give birth than their healthy counterparts.

Nilsen et al. (2012) reported more pregnancies among young women aged 21-24 who had experienced adolescent depression. This pattern continues when looking at even younger ages at first child with Olsson, Hansson, and Cederblad (2006) revealing increased prevalence of teenage parenthood among former mental health inpatients compared to the general Swedish population. The relationship between mental health problems and teenage parenthood has also been found in studies of psychiatric disorders among women and men, based on archival and retrospective survey data (Barett et al., 2015; Kessler 1997 respectively), and in studies looking at aggression and delinquent behaviour (Gaudie et al., 2010).

Co-occurring social disadvantages may muddle the relationship between mental health and teenage parenthood. Hall, Kusunoki, Gatny and Barber (2014) found that depression is correlated with an elevated risk of teenage motherhood but this association ceased to be significant after controlling for socioeconomic factors. Mollborn and Morningstar (2009) observed that mental distress was not a significant predictor of teenage childbearing except for teens living below the poverty line.

Summing up, it appears that mental health issues are associated with teenage parenthood. However, it remains unclear whether this relationship is causal or spurious (e.g. Hall et al., 
2014; Kovacs, Krol, \& Voti, 1994). In yet other cases, mental health together with low socioeconomic status seem to exert a cumulative effect leading to young parenthood (Mollborn \& Morningstar, 2009). Hence, more research is needed in order to disentangle the impact of mental health from other sources of social disadvantage in order to understand the mechanisms behind transition to parenthood in the early life course stages.

\section{This study}

This study investigates the association between teenage parenthood and social and mental health disadvantages. Previous studies have explored the precursors of teenage parenthood. However, this study takes a unique approach by trying to disentangle the experiences of early mental health problems from other social disadvantage factors using data from a population register. Swedish population registers and prescribed-drug registers facilitated the utilisation of longitudinal modelling of the associations between socioeconomic factors, mental health problems, and teenage parenthood for young men and women.

\section{Research questions}

1. Are mental health problems during adolescence associated with becoming a teenage parent, and does this relationship persist even when adjusting for other social disadvantages?

2. What associations between teenage parenthood and other types of social disadvantages can be identified, while controlling for mental health?

\section{Population and data}

The data for this study derived from individuals born in Sweden between 1989 and 1994, pulled from Swedish population registers. In total, $7.9 \%$ of boys and $10.7 \%$ of girls in the population had at least one prescription for psychotropic drugs, preceding childbirth in cases of teenage parents. The proportion of missing values from the data is very low overall due to the nature of the Swedish registers, which have complete data on births and medical prescriptions. The registers had low proportions of missing values in family forms $(0.01 \%)$, income of mother $(1.51 \%$, mother of index person) and age of mother at first child $(0.15 \%$, mother of index person). Attrition rates for age of father at first child (father of index person) and for highest educational level achieved by mother (mother of index person) were $0.53 \%$ and $1.05 \%$, respectively. Individuals with missing data were excluded from the analysis ( $n=13,655,2 \%)$. The final models contained 348,073 men and 332,775 women.

\section{Measures}

The outcome variable teenage parenthood is defined as having a child before age 20 , a cut-off in line with international public health statistics and previous research (e.g. Darroch, Singh, \& Frost, 2001; World Bank, 2016). Teenage parenthood rates in Sweden are lower than in other western countries (Darroch, Singh, \& Frost, 2001), with about 5.6 births occurring per 1,000 women aged 15-19 in 2014 (World Bank, 2016).

The outcome having a child as a teenager could be repeated for a given individual, and there were 348 instances of individuals having a second child while still a teenager. The six cohorts used included 6,984 teenage parents, of which $75 \%(n=5,205)$ were women and $25 \%(n=1,779)$ were men.

Mental health was measured using psychotropic drug prescriptions as a proxy for mental health issues. The records were extracted from the prescribed drugs register, where data from 2005 to 2010 were available. The variable used is a binary variable and denotes whether there was at least one instance of drug prescription per six-month period, and was lagged by 12 months to avoid the risk of the pregnancy being the reason for the mental health issue.

\section{Covariates}

Although the prevalence of teenage parenthood is higher among women than men, previous studies have shown that the risk factors connected to teenage parenthood do not differ between sexes (Woodward, Fergusson, \& Horwood, 2006), except for maternal age and exposure to parental separation.

Mother's (of teenage parent) age at first child and Father's (of teenage parent) age at first child aim to capture intergenerational transitions of family forming patterns, which has proven significant in previous studies (e.g. Murphy \& Wang, 2001; Sipsma, Biello, Cole-Lewis, \& Kershaw, 2010; Wahn \& Nissen, 2008). The ages of mothers and fathers were grouped into three categories each: teenage parenthood ( $<20$ years), early parenthood (20-27 years), and later parenthood ( $>27$ years) for mothers; and teenage parenthood $(<20$ years), early parenthood (20-29 years), and later parenthood ( $>29$ years) for fathers. The cut-off 
between early and later parenthood was chosen with respect to the mean age at first child in Sweden for mothers and fathers, respectively, during the year of birth for the study cohorts.

Socioeconomic position is considered a stable precursor of teenage parenthood (Al-Sahab et al., 2012; Geronimus \& Korenman, 1993; Väisaenen \& Murphy, 2014) and was measured by observing two variables. One variable, highest education of mother, originally contained seven categories spanning from $<9$ years of compulsory school to a doctoral degree, but for the analysis were recoded into three categories: nine years or less of compulsory school, senior high school and higher education. This, to simplify the model while still maintaining important breaks in the education trajectories. Analysis with the full seven-category variable yielded no additional significant differences between the education categories. The second, mother's income, involved earned incomes averaged over five years (index persons' ages 8-13) and divided into quartiles.

Previous studies show an association between family form and teenage parenthood (Fomby \& Bosick, 2013; Woodward, Fergusson, \& Horwood, 2006; Vikat, Rimpela, Kosunen \& Rimpela, 2002). Based on the mother's civil status, family form was measured until the index person reached age 13 and thus became 'at risk' of teenage parenthood. The mother could be denoted as married, cohabitating, in partnership (legal union for homosexual relationships in Sweden pre-2009), or single.

Any shift in status each year from the previous year was recorded, and family form was classified into the following categories: Two adults, stable throughout childhood; Single and stable through childhood; Parent passed away, when the individual lost one or two parents at any point during childhood; family disruption, mothers household went from two adults to one at any point during childhood; and Step family, when the individual gained a parent but did not experience later disruption during the study period. Since some of the mothers $(0.7-1.2 \%$ per year) were missing data for at least one of the 13 years, missing values were replaced by last known status.

Teenage fertility rates differ between countries, (Nordic countries have especially low rates (Darroch et al. 2001)), as well as within Sweden (with increased prevalence in rural settings (Statistics
Sweden 2016)). Therefore, I included two variables adjusting for birthplace of mother and population density in the region of upbringing (measured at the start of the risk period). These variables can influence the propensity of becoming a teenage parent through varying social norms about expected age at first child in these different contexts.

Birthplace of mother was categorised into the Nordic countries (Sweden, Norway, Denmark, Finland and Iceland), the remainder of Europe and other western countries (US, Canada, Australia, New Zealand), or 'Other'.

The variable regions consisted of five regions, and all Swedish municipalities were divided into homogenous regions based on population density, and not geographic location. Municipality divisions were conducted with the help of categories created by Statistics Sweden (2003). The first category, Metropolitan, includes the three largest cities in Sweden and their closely surrounding areas. The second category, Bigger cities, comprised municipalities with $>90,000$ inhabitants within a $30-\mathrm{km}$ radius of the municipality centre, the most densely populated area in the municipality. Category 3, Smaller cities, included municipalities with $>27,000$ but $<90,000$ inhabitants within a 30$\mathrm{km}$ radius, and $>300,000$ inhabitants within a 100$\mathrm{km}$ radius of the municipality centre. Category 4, Semi-rural areas, comprised municipalities who also had $>27,000$ but $<90,000$ inhabitants within a 30$\mathrm{km}$ radius, and $<300,000$ inhabitants within a 100$\mathrm{km}$ radius, of the municipality centre. Lastly, rural areas included the remaining municipalities with < 27,000 within a $30-\mathrm{km}$ radius from the municipality centre. Region of residency was measured at age 13 , which is considered the start of the 'at risk' period for teenage parenthood.

\section{Statistical analysis}

The research questions were addressed through panel data models, specifically random effects models. This type of model makes it possible to analyse the probability of having a child during teenage years, conditional on both the time-varying covariate drug prescriptions, as well as the other time-fixed covariates. The models, utilising person specific intercepts, allow error terms and random effects to have correlated variability enabling repeated measures of the same individuals. The individuals were followed from before turning 13 until turning 20 in six-month intervals, resulting in 
15 person periods per individual. The time-varying mental health variable 'Prescriptions' was individual mean centred, which constitutes using the individual mean for the time-varying variable as a control in the model. Hence, the variability around each individual's mean was modelled, thereby solving issues of unobserved heterogeneity and selection (Curran \& Bauer, 2011).

The models were run separately for men and women, and included a variable controlling for time to account for the fact that the prevalence of teenage parenthood increases in later years. Intergenerational transmission of fertility was tested for both men and women using both the mother's and father's age at first child, and the model with the strongest effects was chosen, in order to provide the best control available while estimating the effect of mental health prescriptions and other social disadvantage measures. Variance influence factors (VIFs) were used to check for multicollinearity among the covariates. Sensitivity analyses were performed by calculating fixed effects models with the outcome teenage pregnancy and the time-varying variable prescriptions. The fixed effects models had comparable results, although the random effects models yielded more conservative coefficients. Moreover, the random effect models were calculated using increasing integration points up to 100 with stable coefficients.

\section{Results}

I ran separate random intercept logistic models for men and women to investigate whether mental health issues in youth are associated with later teenage motherhood and fatherhood. Model 1 contained: the variable prescriptions for measuring mental health issues, a mean-centring variable for prescriptions, and a time variable (not reported) accounting for the fact that most teenage births occur in later adolescent years. The models for women included 331,775 individual and the models for men 348,073 individuals. The prevalence of having at least one instance of prescriptions for psychotropic drugs were $7.94 \%$ for men and $10.67 \%$ for women, and the proportion of individuals becoming teenage parents were $0.5 \%$ of men and $1.54 \%$ of women. Background variables were added to model 2 to determine whether mental health issues was still significant in the presence of other types of social disadvantages and other known predictors of teenage parenthood, while at the same time, revealing if these factors were relevant for both teenage mothers and teenage fathers in this setting. Complete descriptive of all variables included in the models can be found in the appendix, table A1.

As table 1 illustrates, model 1 shows that mental health problems in youth lead to an almost threefold increase in the odds of becoming a teenage father, and a 2.6-fold increase in the odds of becoming a teenage mother. After adding the other disadvantage variables and contextual background variables in model 2 , the association remains and even grows stronger as factors such as patterns in intergenerational transmission of fertility, income, and the mother's education is included. The connection between mental health problems and teenage parenthood remains strong for both boys $(O R=3.68)$ and girls $(O R=5.12)$. Running a pooled model with both boys and girls (not shown) interacting gender and prescriptions reveals that mental health problems do indeed have a larger impact for women (CI95\% OR 3.69 - 5.55 for prescriptions in reference to no prescriptions) than for men (CI95\% OR $1.99-3.08$ for prescriptions in reference to no prescriptions). 
Table 1. Random intercept logistic models for teenage parenthood in girls and boys.

\begin{tabular}{|c|c|c|c|c|}
\hline & $\begin{array}{l}\text { Model } 1 \\
\text { Men } \\
\text { OR (Cl 95\%) }\end{array}$ & $\begin{array}{l}\text { Model } 2 \\
n=348,073 \\
\text { OR (Cl 95\%)) }\end{array}$ & $\begin{array}{l}\text { Model } 1 \\
\text { Women } \\
\text { OR (Cl 95\%)) }\end{array}$ & $\begin{array}{l}\text { Model } 2 \\
n=331,775 \\
\text { OR (CI 95\%)) }\end{array}$ \\
\hline Prescriptions & $2.85^{* * *}(2.35-3.45)$ & $3.68 * * *(2.06-6.56)$ & $2.53^{* * *}(2.28-2.81)$ & $5.12 * * *(3.60-7.30)$ \\
\hline \multicolumn{5}{|c|}{ Fathers / Mothers age at first child } \\
\hline Teenage parent & & $3.75 * * *(2.73-5.16)$ & & $2.57^{* * *}(2.29-2.89)$ \\
\hline Young parent & & $1.31 * * *(1.18-1.45)$ & & $1.35^{* * *}(1.27-1.44)$ \\
\hline Later parent & & Ref. & & Ref. \\
\hline \multicolumn{5}{|c|}{ Highest completed education, Mother } \\
\hline 9 years or less & & $3.18^{* * *}(2.70-3.74)$ & & $3.93^{* * *}(3.54-4.37)$ \\
\hline Senior high school & & $1.76^{* * *}(1.53-2.02)$ & & $2.20 * * *(2.01-2.41)$ \\
\hline Higher education & & Ref. & & Ref. \\
\hline \multicolumn{5}{|c|}{ Highest completed education, Mother $x$ Prescriptions } \\
\hline 9 years or less & & $0.96 \quad(0.51-1.80)$ & & $0.58^{* * *}(0.41-0.83)$ \\
\hline Senior high school & & $1.00 \quad(0.57-1.75)$ & & $0.89 \quad(0.66-1.19)$ \\
\hline Higher education & & Ref. & & Ref. \\
\hline \multicolumn{5}{|l|}{ Maternal income } \\
\hline Quartile 1 & & $2.37 * * *(1.98-2.84)$ & & $2.87^{* * *}(2.56-3.22)$ \\
\hline Quartile 2 & & $1.75^{* * *}(1.45-2.11)$ & & $1.98^{* * *}(1.76-2.23)$ \\
\hline Quartile 3 & & $1.43^{* * *}(1.18-1.74)$ & & $1.57^{* * *}(1.38-1.77)$ \\
\hline Quartile 4 & & Ref. & & Ref. \\
\hline \multicolumn{5}{|c|}{ Maternal Income $x$ Prescriptions } \\
\hline Quartile 1 & & $0.72 \quad(0.38-1.34)$ & & $0.49 * * *(0.35-0.68)$ \\
\hline Quartile 2 & & $0.67 \quad(0.35-1.32)$ & & $0.64 * *(0.45-0.91)$ \\
\hline Quartile 3 & & $0.79 \quad(0.39-1.57)$ & & $0.50 * * *(0.34-0.73)$ \\
\hline Quartile 4 & & Ref. & & Ref. \\
\hline \multicolumn{5}{|l|}{ Family form } \\
\hline Two adult household & & Ref. & & Ref. \\
\hline Step family & & $1.98^{* * *}(1.54-2.54)$ & & $2.31 * * *(1.98-2.66)$ \\
\hline Single adult household & & $2.31 * * *(1.85-2.88)$ & & $3.06 * * *(2.71-3.46)$ \\
\hline Divorce/separation & & $2.11^{* * *}(1.89-2.36)$ & & $2.42^{* * *}(2.27-2.59)$ \\
\hline Parent passed away & & $2.16^{* * *}(1.71-2.73)$ & & $2.80 * * *(2.45-3.19)$ \\
\hline \multicolumn{5}{|l|}{ Region } \\
\hline Metropolitan & & Ref. & & Ref. \\
\hline Bigger cities & & $1.35 * * *(1.18-1.54)$ & & $1.32^{* * *}(1.22-1.42)$ \\
\hline Smaller cities & & $1.38^{* * *}(1.18-1.60)$ & & $1.41^{* * *}(1.29-1.54)$ \\
\hline Semi-rural areas & & $1.65^{* * *}(1.35-2.03)$ & & $1.44^{* * *}(1.27-1.63)$ \\
\hline Rural areas & & $1.46^{* * *}(1.19-1.81)$ & & $1.62^{* * *}(1.44-1.83)$ \\
\hline \multicolumn{5}{|l|}{ Region of origin, Mother } \\
\hline Scandinavia & & Ref. & & Ref. \\
\hline Europe and West & & $1.43 * * \quad(1.12-1.82)$ & & $0.96 \quad(0.81-1.13)$ \\
\hline Other & & $0.63^{* * *}(0.50-0.80)$ & & $0.63^{* * *}(0.55-0.72)$ \\
\hline $\mathrm{AIC}$ & 28140.07 & 27231.31 & 72423.98 & 68662.70 \\
\hline
\end{tabular}

Note: ${ }^{*} \mathrm{p}<.05 .{ }^{* *} \mathrm{p}<.01 * * * \mathrm{p}<.001$ 
Moreover, model 2 revealed a significant interaction between mental health-related prescriptions and mother's income for girls. This demonstrated that the association between mental health issues and becoming a teenage mother is stronger among girls from the highest income quartile, compared to all other income quartiles. No such statistical significant interactions were found for boys. The same pattern can be seen when interacting maternal education with prescriptions, with a larger impact among women from mothers with higher education compared to women whose mother had nine years or less of education. Again, this is only true for women, and no statistically significant differences were found in the impact of prescription on the probability of teenage parenthood in the different education categories for men.

Model 2 was intended to determine the remaining associations between teenage parenthood and other social disadvantages while controlling for mental health. This model demonstrated that low socioeconomic position, measured by low maternal education and income, increased the probability of teenage parenthood for both boys and girls, with education being a more important factor than income. Teenage parenthood was the least likely among children from homes with maternal tertiary education, followed by senior high school, with highest likelihood among nine years of schooling or less.

Additionally, teenage parenthood appeared less likely to occur within a traditional nuclear family setting. Individuals from all the family forms measured (single, divorced, step family, and parental loss), were more likely to become teenage parents than individuals from a stable two-adult household. The single parent household, either through divorce or parental loss, held the highest propensity for teenage births for both girls and boys.

The data showed that intergenerational transmission of fertility plays an important role for both boys and girls, although differences were evident. For boys, fathers' age at birth of first child had the strongest impact, whereas for girls, age at which her mother had her first child was strongest. If the parent had the first child as a teenager, the children were more likely to become teenage parents too, compared to parents who had their first child at a later age. Lastly, individuals living in less densely populated areas at age 13 were more likely to become teenage parents, suggesting that these different types of regions may assert different normative expectations about age at birth of first child. Furthermore, controlling for the birth country of the mother showed that second-generation immigrant youth from outside of European and Western contexts were less likely to become teenage parents than Scandinavian and European/Western descendants. This association was driven by second-generation immigrants from countries that all had substantive representation in the population, while at the same time having very low teenage parenthood rates. These were countries or regions such as Cyprus/Turkey, the former Yugoslavian republics, Syria/Lebanon/ Jordan/Palestine and Iran/Afghanistan/Pakistan/ Bangladesh.

\section{Discussion}

It has been argued that the relationship between mental health and teenage pregnancy might be explained by the connection of social disadvantage and mental health (Hall et al., 2014). However, my results show that mental health problems in youth function as an independent predictor of teenage parenthood, even after adjusting for other social disadvantage factors, in line with some previous research (e.g. Olsson, Hansson, \& Cederblad, 2006; Barett et al., 2015; Kessler et al., 1997). In addition, my results expand on previous knowledge by showing that this is true for both boys and girls. Altogether, this illustrates that mental health problems, on their own, are an important area of research concerning the family patterns and life trajectories of young people.

The strength of the association between mental health and teenage parenthood could relate to feelings of fewer work and education opportunities, and hence low opportunity costs of early parenthood. The perception of fewer education and work opportunities might trigger an increased need for meaning, fulfilment and uncertainty reduction to be met through parenthood. Such perceptions could increase the value placed on children by youth with mental health problems as well as other types of social disadvantage.

Interestingly, mental health problems interacted with other social disadvantages in a manner unlike the one identified by Mollborn and Morningstar 
(2009). They saw mental health problems becoming significant only within the low-income group. On the contrary, my results show that the association between mental health problems and teenage parenthood were even stronger among highincome girls and girls of homes with high maternal education levels. While Mollborn and Morningstar (2009) saw a cumulative disadvantage, i.e. when several disadvantages converge to become a risk factor, in their American study, this Swedish study divergence from the expected life course seemed to be a more influential risk factor. The combination of mental health problems and origins in a high income and education household might sharpen the contrast between the expected and anticipated educational and income trajectories. Parental class is shown to be a strong predictor for teenage educational and occupational aspirations (Baker et al., 2014; Schoon \& Parsons, 2002; McCulloch, 2017). In turn, higher educational aspirations should lead to postponement of other central life course events, such as childbearing, since more years are needed in education, as argued by Crockett and Beal (2012). A sharp contrast between these normatively expected trajectories and the individual lived reality for these young women with mental health issues, could lead young women to choose parenthood as a means of reducing uncertainty to a greater extent.

In addition, analyses of the associations between teenage parenthood and social disadvantage, while controlling for mental health, revealed that low socioeconomic status, measured by low maternal education and income, increased the probability of teenage parenthood for both boys and girls. This finding aligns with persistent results from various environments over time (Väisanen \& Murphy, 2014) that also demonstrate a stronger association between decreased probability of teenage parenthood and mother's education than between the former and mother's income. Education may be a better indicator of the cultural capital associated with transference of norms and values surrounding family, and may also imply that economic capital does not have as strong an influence on the shaping of family decisions.

Variables such as family form, age of parents at birth of first child and location also showed a persistent association with teenage parenthood, even in the presence of mental health measures. Living in an intact nuclear family seemed to decrease the chances of teenage parenthood, while having a parent who had their first child as a teenager increased it. Intergenerational transmission of fertility remained a pervading predictor of teenage parenthood, in line with previous research (Murphy \& Wang, 2001; Sipsma et al., 2010; Wahn \& Nissen, 2008). Interestingly, sex was a crucial factor of this predictor, as girls had the strongest association with their mother becoming a teenage parent, while for boys the age at birth of first child of fathers had the strongest impact.

A unique strength of this study is the inclusion of teenage fathers as well as teenage mothers. Far less data on the health and background of teenage fathers is available, which may partly be due to low prevalence and recruitment challenges. Attempts to include teenage fathers in studies of the precursors and consequences of young parenthood are essential. The increased participation of men in family life has been dubbed the second part of the gender revolution (Goldscheider, Bernhardt, \& Lappegård, 2015). Fulfilling the desire to encourage parental equality, with fathers taking an active part of their children's lives, requires knowledge about both mothers and fathers.

A limitation of this study is the measure used to denote mental health problems. The data from the drugs register provided rich and comprehensive information about drugs prescribed for mental health issues, and prescription data has previously been utilised as proxies for somatic health issues (e.g. Baranowska-Rataj, DeLuna \& Ivarsson, 2016) as well as mental health issues (e.g. Brännlund, Strandh \& Nilsson, 2017; Norström, Lindberg \& Månsdotter, 2012). However, the youth in this study who were categorised as having had mental health problems were only those who sought treatment, and were prescribed psychotropic drugs. This does not capture individuals who are referred to psychologists (without receiving prescription medication), or individuals who do not seek treatment at all. Both the groups who did not seek support from the healthcare system and those referred to psychological treatments might differ from the group with mental health problems treated through pharmacology. However, Sweden has seen an overall increase of the prescription of psychotropic drugs for both issues such as depression, anxiety and sleeping problems and ADHD over the last decade (The National Board for 
Health and Welfare, 2017). Still, it is important to remember that this measure is a proxy for certain types of serious mental health issues demanding medication. Moreover, this study does not have the possibility to capture what type of mental health issues the prescriptions targets, which would be an interesting venue for further research.

The results presented here have implications for both policy and professionals. An awareness of the association between mental health problems (and other types of social disadvantages) and teenage parenthood informs the professional that teenage parents constitute a group at risk of later adverse outcomes for both parent and child. This knowledge can be used to better identify individuals with special support needs. However, young parenthood is not necessarily negative. Even so, age is readily available information that might indicate a heightened probability of mental health problems, which, in turn, might present additional challenges for both parent and child.

It is critical not to assume that mental health problems are present in all teenage parents. In reality, most children of young parents do not experience adverse outcomes (Shaw, Lawlor, \& Najman, 2006). Young parenthood breaks the normative expectations of fertility behaviour, and young mothers in particular have expressed feelings of stigmatisation by society as one of the hardest challenges of parenthood (Wahn, Nissen, \& Ahlberg, 2005). Teenage parents might experience others' assumption of the presence of mental health problems or adverse family backgrounds as further stigmatisation. These issues require careful consideration by the professional.

Activities aimed at increasing the perceived life opportunities of youth and giving significance to life may be considered as means of preventing teenage parenthood through policy. This study suggests that such activities could be extended to include teenagers with mental health problems. However, prevention of teenage parenthood should not be the sole focus of these activities. If policymakers fear that teenage parenthood will lead to decreased life opportunities and negative health outcomes for both parent and child via pathways of social disadvantage, then policy should target facilitation of restarting and completion of education. This point has already been argued by Lawlor and Shaw (2002).

Lastly, future research should concentrate on elucidating the motivations of teenage parents today, and on the ways in which policy can facilitate creation and maintenance of positive lifelong outcomes for the parents themselves and for their children.

\section{Acknowledgements}

The Umeå SIMSAM Lab data infrastructure used in this study was developed with support from the Swedish Research Council and by strategic funds from Umeå University.

\section{References}

Al-Sahab, B., Heifetz, M., Tamim, H., Bohr, Y., \& Connolly, J. (2012). Prevalence and characteristics of teen motherhood in Canada. Maternal and Child Health Journal, 16(1), 228-234. https://doi.org/10.1007/s10995-011-0750-8

Baker, W., Sammons, P., Siraj-Blatchford, I., Sylva, K., Melhuish, E. C., \& Taggart, B. (2014). Aspirations, education and inequality in England: Insights from the Effective Provision of Pre-school, Primary and Secondary Education Project. Oxford Review of Education, 40(5), 525-542. https://doi.org/10.1080/03054985.2014.953921

Baranowska-Rataj, A., de Luna, X., \& Ivarsson, A. (2016). Does the number of siblings affect health in midlife? Evidence from the Swedish Prescribed Drug Register. Demographic Research, 35, 1259-1302. https://doi.org/10.4054/DemRes.2016.35.43

Barrett, D. E., Katsiyannis, A., Zhang, D., \& Kingree, J. B. (2015). Predictors of teen childbearing among delinquent and non-delinquent females. Journal of Child and Family Studies, 24(4), 970-978. https://doi.org/10.1007/s10826-014-9907-6 
Becker, G. S. (1960). An economic analysis of fertility. In Roberts, G., B. (Ed.), Demographic and Economic Change in Developed Countries (pp. 209-240). New York: Columbia University Press. Retrieved from http://www.nber.org/chapters/c2387

Buchanan, J. M. (2008). Opportunity cost. In S. N. Durlauf \& L. E. Blume (Eds.), The New Palgrave Dictionary of Economics. Basingstoke: Palgrave Macmillan. Retrieved from http://www.dictionaryofeconomics.com/extract?id=pde2008 0000029 https://doi.org/10.1057/978-1-349-95121-5 1433-2

Braveman, P., \& Gruskin, S. (2003). Defining equity in health. Journal of Epidemiology and Community Health, 57(4), 254-258. https://doi.org/10.1136/jech.57.4.254

Brännlund, A., Strandh, M., \& Nilsson, K. (2017). Mental-health and educational achievement: the link between poor mental-health and upper secondary school completion and grades. Journal of Mental Health, 26(4), 1-8. https://doi.org/10.1080/09638237.2017.1294739

Carlson, D. L. (2011). Explaining the curvilinear relationship between age at first birth and depression among women. Social Science \& Medicine, 72(4), 494-503. https://doi.org/10.1016/j.socscimed.2010.12.001

Crockett, L. J., \& Beal, S. J. (2012). The life course in the making: Gender and the development of adolescents' expected timing of adult role transitions. Developmental Psychology, 48(6), 1727-1738. https://doi.org/10.1037/a0027538

Cunnington, A. J. (2001). What's so bad about teenage pregnancy? Journal of Family Planning and Reproductive Health Care, 27(1), 36-41. https://doi.org/10.1783/147118901101194877

Curran, P. J., \& Bauer, D. J. (2011). The disaggregation of within-person and between-person effects in longitudinal models of change. Annual Review of Psychology, 62(1), 583-619. https://doi.org/10.1146/annurev.psych.093008.100356

Darroch, J. E., Singh, S., \& Frost, J. J. (2001). Differences in teenage pregnancy rates among five developed countries: The roles of sexual activity and contraceptive use. Family Planning Perspectives, 33(6), 244-250 \& 281. https://doi.org/10.2307/3030191

Fomby, P., \& Bosick, S. J. (2013). Family instability and the transition to adulthood: Family instability and the transition to adulthood. Journal of Marriage and Family, 75(5), 1266-1287. https://doi.org/10.1111/jomf.12063

Friedman, D., Hechter, M., \& Kanazawa, S. (1994). A theory of the value of children. Demography, 31(3), 375-401. https://doi.org/10.2307/2061749

Furstenberg, F. F. (1991). As the Pendulum Swings: Teenage Childbearing and Social Concern. Family Relations, 40(2), 127-138. https://doi.org/10.2307/585470

Gaudie, J., Mitrou, F., Lawrence, D., Stanley, F. J., Silburn, S. R., \& Zubrick, S. R. (2010). Antecedents of teenage pregnancy from a 14-year follow-up study using data linkage. Bmc Public Health, 10, 63. https://doi.org/10.1186/1471-2458-10-63

Geronimus, A., \& Korenman, S. (1992). The socioeconomic consequences of teen childbearing reconsidered. Quarterly Journal of Economics, 107(4), 1187-1214. https://doi.org/10.2307/2118385

Geronimus, A., \& Korenman, S. (1993). The socioeconomic costs of teenage childbearing - evidence and interpretation. Demography, 30(2), 281-290. https://doi.org/10.2307/2061842

Gibb, S. J., Fergusson, D. M., Horwood, L. J., \& Boden, J. M. (2015). Early motherhood and long-term economic outcomes: Findings from a 30-year longitudinal study. Journal of Research on Adolescence, 25(1), 163-172. https://doi.org/10.1111/iora.12122

Goldscheider, F., Bernhardt, E., \& Lappegård, T. (2015). The gender revolution: A framework for understanding changing family and demographic behavior. Population and Development Review, 41(2), 207-239. https://doi.org/10.1111/j.1728-4457.2015.00045.x

Hall, K. S., Kusunoki, Y., Gatny, H., \& Barber, J. (2014). The risk of unintended pregnancy among young women with mental health symptoms. Social Science \& Medicine, 100, 62-71. Hoffman, L., \& Hoffman, M. (1973). The value of children to parents. In J. T. Fawcett (Ed.), Psychological perspectives on population (Vol. 1973, pp. 19-76). New York: Basic Books. https://doi.org/10.1016/i.socscimed.2013.10.037 
Hoffman, L., Thornton, A., \& Manis, J. (1978). Value of children to parents in the United States. Journal of Population, 1(2), 91-131. https://doi.org/10.1007/BF01277597

Jonsson, U., Bohman, H., Hjern, A., von Knorring, L., Paaren, A., Olsson, G., \& von Knorring, A. L. (2011). Intimate relationships and childbearing after adolescent depression: a population-based 15 year follow-up study. Social Psychiatry and Psychiatric Epidemiology, 46(8), 711-721. https://doi.org/10.1007/s00127-010-0238-7

Kalucza, S., Hammarström, A., \& Nilsson, K. (2015). Mental health and parenthood - A longitudinal study of the relationship between self-reported mental health and parenthood. Health Sociology Review, 114. https://doi.org/10.1080/14461242.2015.1051079

Kessler, R. C., Berglund, P. A., Foster, C. L., Saunders, W. B., Stang, P. E., \& Walters, E. E. (1997). Social consequences of psychiatric disorders, II: Teenage parenthood. The American Journal of Psychiatry, 154(10), 1405-1411. https://doi.org/10.1176/ajp.154.10.1405

Kovacs, M., Krol, R. S. M., \& Voti, L. (1994). Early onset psychopathology and the risk for teenage pregnancy among clinically referred girls. Journal of the American Academy of Child \& Adolescent Psychiatry, 33(1), 106-113. https://doi.org/10.1097/00004583-199401000-00014

Lawlor, D. A., \& Shaw, M. (2002). Too much too young? Teenage pregnancy is not a public health problem. International Journal of Epidemiology, 31(3), 552-554. https://doi.org/10.1093/ije/31.3.552

Link, B. G., Phelan, J. C., Bresnahan, M., Stueve, A., \& Pescosolido, B. A. (1999). Public conceptions of mental illness: Labels, causes, dangerousness, and social distance. American Journal of Public Health, 89(9), 1328-1333. https://doi.org/10.2105/AJPH.89.9.1328

Moilanen, K. L. (2015). Predictors of latent growth in sexual risk taking in late adolescence and early adulthood. Journal of Sex Research, 52(1), 83-97. https://doi.org/10.1080/00224499.2013.826167

Mollborn, S., \& Morningstar, E. (2009). Investigating the relationship between teenage childbearing and psychological distress using longitudinal evidence. Journal of Health and Social Behavior, 50(3), 310326. https://doi.org/10.1177/002214650905000305

McCulloch, A. (2017). Educational aspirations trajectories in England. British Journal of Educational Studies, 65(1), 69-85. https://doi.org/10.1080/00071005.2016.1197883

Murphy, M., \& Wang, D. (2001). Family-level continuities in childbearing in low-fertility societies. European Journal of Population / Revue Européenne de Démographie, 17(1), 75-96. https://doi.org/10.1023/A:1010744314362

Nilsen, W., Olsson, C. A., Karevold, E., O'Loughlin, C., McKenzie, M., \& Patton, G. C. (2012). Adolescent depressive symptoms and subsequent pregnancy, pregnancy completion and pregnancy termination in young adulthood: Findings from the Victorian Adolescent Health Cohort Study. Journal of Pediatric and Adolescent Gynecology, 25(1), 6-11. https://doi.org/10.1016/i.jpag.2011.06.013

Norström, L., Lindberg, L., \& Månsdotter, A. (2012). Could gender equality in parental leave harm off-springs' mental health? A registry study of the Swedish parental/child cohort of 1988/89. International Journal for Equity in Health, 11(1), 19. https://doi.org/10.1186/1475-9276-11-19

Olausson, P. O., Haglund, B., Weitoft, G. R., \& Cnattingius, S. (2001). Teenage childbearing and long-term socioeconomic consequences: A case study in Sweden. Family Planning Perspectives, 70-74. https://doi.org/10.2307/2673752

Olsson, M., Hansson, K., \& Cederblad, M. (2006). A long-term follow-up of conduct disorder adolescents into adulthood. Nordic Journal of Psychiatry, 60(6), 469-479. https://doi.org/10.1080/08039480601022041

Schoon, I., \& Parsons, S. (2002). Teenage aspirations for future careers and occupational outcomes. Journal of Vocational Behavior, 60(2), 262-288. https://doi.org/10.1006/jvbe.2001.1867

Selling, K. E., Carstensen, J., Finnstrom, O., Josefsson, A., \& Sydsjö, G. (2009). Hospitalization in adolescence affects the likelihood of giving birth: a Swedish population-based register study. Acta Paediatrica, 98(3), 561-566. https://doi.org/10.1111/j.1651-2227.2008.01120.x 
Shaw, M., Lawlor, D. A., \& Najman, J. M. (2006). Teenage children of teenage mothers: Psychological, behavioural and health outcomes from an Australian prospective longitudinal study. Social Science \& Medicine, 62(10), 2526-2539. https://doi.org/10.1016/i.socscimed.2005.10.007

Sipsma, H., Biello, K. B., Cole-Lewis, H., \& Kershaw, T. (2010). Like father, like son: The intergenerational cycle of adolescent fatherhood. American Journal of Public Health, 100(3), 517-524. https://doi.org/10.2105/AJPH.2009.177600

Statistics Sweden (2016). Statistical database: Demographic analysis (DEMOG). Available at: http://www.scb.se/be0701-en (accessed 21 October 2016).

Statistics Sweden (2003). Reports on statistical co-ordination for the official statistics of Sweden: Regional divisions in Sweden on 1 January 2003. Part 1. Statistics available at: http://www.scb.se/statistik/OV/OV9999/2003M00/X200P0301.pdf

The National Board of Health and Welfare (2017). Statistikdatabas för läkemedel. Available at: http://www.socialstyrelsen.se/Statistik/statistikdatabas/

Väisaenen, H., \& Murphy, M. (2014). Social inequalities in teenage fertility outcomes: Childbearing and abortion trends of three birth cohorts in Finland. Perspectives on Sexual and Reproductive Health, 46(2), 109-116. https://doi.org/10.1363/46e1314

Vikat, A., Rimpela, A., Kosunen, E., \& Rimpela, M. (2002). Sociodemographic differences in the occurrence of teenage pregnancies in Finland in 1987-1998: a follow up study. Journal of Epidemiology and Community Health, 56(9), 659-668. https://doi.org/10.1136/jech.56.9.659

Wahn, E. H., \& Nissen, E. (2008). Sociodemographic background, lifestyle and psychosocial conditions of Swedish teenage mothers and their perception of health and social support during pregnancy and childbirth. Scandinavian Journal of Public Health, 36(4), 415-423. https://doi.org/10.1177/1403494807085315

Wahn, E. H., Nissen, E., \& Ahlberg, B. M. (2005). Becoming and being a teenage mother: How teenage girls in South Western Sweden view their situation. Health Care for Women International, 26(7), 591-603. https://doi.org/10.1080/07399330591004917

Woodward, L. J., Fergusson, D. M., \& Horwood, L. J. (2006). Gender differences in the transition to early parenthood. Development and Psychopathology, 18(1), 275-294. https://doi.org/10.1017/S0954579406060159

World Bank (2016). World data bank - World development indicators. Available at: http://databank.worldbank.org/data/reports.aspx?source=2\&series=SP.ADO.TFRT\&country=SWE (accessed 26 October 2016). 


\section{Appendix}

Table A1. Descriptive statistics of study variables

\begin{tabular}{|c|c|c|}
\hline Variable & $\begin{array}{l}\text { Men, n 348,073 } \\
\%(n)\end{array}$ & $\begin{array}{l}\text { Women, n 331,775 } \\
\%(n)\end{array}$ \\
\hline Teenage parents & $0.50(1740)$ & $1.54(5109)$ \\
\hline Prescriptions & 7.94 (27637) & $10.67(35412)$ \\
\hline \multicolumn{3}{|l|}{ Mothers age at first child } \\
\hline Teenage parent & $2.49(8655)$ & $2.51(8315)$ \\
\hline Young parent & 46.61 (162224) & $46.58(154554)$ \\
\hline Older parent & 50.91 (177194) & $50.91(168906)$ \\
\hline \multicolumn{3}{|l|}{ Fathers age at first child } \\
\hline Teenage parent & $0.54(1888)$ & $0.55(1824)$ \\
\hline Young parent & 44.74 (155715) & $44.50(147643)$ \\
\hline Older parent & 54.72 (190470) & $54.47(180721)$ \\
\hline \multicolumn{3}{|l|}{ Highest education of mother } \\
\hline 9 years or less & $11.23(39088)$ & $11.23(37273)$ \\
\hline High school (Gymnasium) & 57.83 (201299) & 57.85 (191924) \\
\hline Higher education & $30.94(107686)$ & 30.92 (102578) \\
\hline \multicolumn{3}{|l|}{ Family form } \\
\hline Stably two adults & $60.01(209176)$ & 59.59 (197709) \\
\hline Stably single & $3.19(11103)$ & $3.43(11411)$ \\
\hline Diseased, one or two & $3.06(10640)$ & $3.11(10324)$ \\
\hline Family disruption & 30.73 (106987) & $30.95(102668)$ \\
\hline Family merger & $2.92(10167)$ & $2.91(9663)$ \\
\hline \multicolumn{3}{|l|}{ Regions } \\
\hline Metropolitan & $28.94(100736)$ & 28.89 (95851) \\
\hline Bigger cities & 38.86 (135255) & 38.91 (129078) \\
\hline Smaller cities & 19.36 (67391) & $19.45(64517)$ \\
\hline Semi-rural areas & $6.30(21939)$ & $6.26(20756)$ \\
\hline Rural areas & $6.56(22752)$ & $6.50(21573)$ \\
\hline \multicolumn{3}{|l|}{ Earned income of mother } \\
\hline Quartile 1 & $0-146163$ & $0-146163$ \\
\hline Quartile 2 & $146163-188861$ & $146163-188861$ \\
\hline Quartile 3 & $188861-236685$ & $188861-236685$ \\
\hline Quartile 4 & $236685-7471743$ & $236685-7471743$ \\
\hline \multicolumn{3}{|l|}{ Birth country of Mother } \\
\hline Scandinavia & 90.59 (315324) & 90.62 (300646) \\
\hline Europe and West & $3.29(11450)$ & $3.37(11180)$ \\
\hline Other & $6.12(21297)$ & 6.01 (19947) \\
\hline
\end{tabular}

